\title{
THE ECONOMIC AND SOCIAL IMPACT OF TELEWORKING IN ROMANIA: PRESENT PRAGTICES AND POST PANDEMIC DEVELOPMENTS
}

\author{
Syed Abdul Rehman Khan ${ }^{1}$, Danish Iqbal Godil ${ }^{2}$, Munaza Bibi ${ }^{3}$, \\ Zhang $\mathbf{Y u}^{4 *}$ and Syed Muhammad Ahsan Rizvi ${ }^{5}$ \\ ${ }^{1)}$ Xuzhou University of Technology, Xuzhou, China and Beijing Key Laboratory \\ of Urban Spatial Information Engineering, Beijing, China \\ ${ }^{2)}$ Dar-ul-Madina International University, Islamabad, Pakistan \\ 3,5) Bahria University, Karachi, Pakistan \\ ${ }^{4)}$ Chang'an University, Xi'an, China
}

Please cite this article as:

Khan, S.A.R., Godil, D.I., Bibi, M., Yu, Z. and Rizvi,

S.M.A., 2021. The Economic and Social Impact of

Teleworking in Romania: Present Practices and Post

Pandemic Developments. Amfiteatru Economic, 23(58), pp. 787-804.

DOI: $10.24818 / \mathrm{EA} / 2021 / 58 / 787$

Article History

Received: 25 March 2021

Revised: 12 May 2021

Accepted: 17 June 2021

\begin{abstract}
The emergence of COVID-19 has drastically transformed the way people are working along with that the productivity of firms is also affected due to this catastrophic event that happened at the end of the year 2019. The teleworking aspect has gained momentum during COVID-19 and it has been used extensively by the firms to maintain their operations. This study aims to examine the impact of COVID-19 policies, adoption of advanced technology, and teleworking on firm productivity in Romania with a sample of 328 including the Vice President, Operation Manager, General manager, Logistics Manager, Procurement Manager, and Information system manager while the collected data was analyzed using the CB SEM technique. After analyzing the collected data, we have found that the COVID-19 pandemic plays an imperative role in increasing teleworking practices in Romania, while the COVID-19 pandemic is not viewed as a significant factor in the adoption of advanced technology in Romania. On the other side, this pandemic negatively affects Romania's firm productivity, whereas teleworking and the adoption of advanced technology positively affect the Romanian firms' productivity. Lastly, the adoption of advanced technology helps in increasing the pattern of teleworking in Romania. The increased use of teleworking practices has been regarded as an important practice in Romania to follow the COVID-19 policies imposed by the government on one side, yet to keep the business operation in the smooth run by working from home through employing the technology to maintain the firm productivity.
\end{abstract}

Keywords: Teleworking, COVID-19, Firms Productivity, Smart technologies.

JEL Classification: E10, F14, M10, M21

*Corresponding author, Zhang Yu - e-mail: zhangyu19@foxmail.com

Authors' ORCID:

Syed Abdul Rehman Khan: https://orcid.org/0000-0001-5197-2318

Danish Iqbal Godil: https://orcid.org/0000-0003-1602-3744

Munaza Bibi: https://orcid.org/0000-0001-9094-7262

Zhang Yu: https://orcid.org/0000-0002-9499-6157

Syed Muhammad Ahsan Rizvi: https://orcid.org/0000-0001-5725-2733

Vol. $23 \cdot$ No. $58 \cdot$ August 2021 


\section{Introduction}

A triple-edged sword - COVID-19 has brought several challenges that have transformed the world by having a noteworthy influence on society and economic perspectives across every sector and business around the globe (Kamal, 2020). The emergence of catastrophic events in COVID-19 has changed the way people are working routinely. Principally, every sector of business has shifted their way of working from a traditional office environment towards using the technology to fulfill customers' demands, employees, and maintaining business through working from home. Accordingly, teleworking is seen as a major rejoinder for business continuity in response to the COVID-19 crisis. In a parallel vein, several organizations have allowed their employees to work remotely via technological support to fulfill their duties (Belzunegui-Eraso and Erro-Garcés, 2020).

Furthermore, teleworking is regarded as a beneficial aspect during COVID-19 for organizations, yet it posits numerous challenges for managers to manage employees in such a scenario. According to the Organisation for Economic Co-operation Development (2020), the adoption of teleworking practices during the COVID-19 crisis has an unpredictable impact on productivity and other indicators and these effects will persist after this pandemic. Therefore, firms need to make investments to address the possible concerns regarding innovation, such as the use of technology, teleworking practices, and workers' well-being. As Groen, Van Triest, Coers and Wtenweerde (2018) found that teleworking is linked positively to the emphasis put forward on output. Simultaneously, teleworking is seen as an occasional strategy adopted by companies in response to the health catastrophe. As Belzunegui-Eraso and Erro-Garcés (2020) also viewed that organization needs to plan for teleworking not just as an occasional facet that is derived either from environmental or health events, yet it is perhaps regarded as a strategy for reduction of the cost that is linked to infrastructure along with the creation of a favourable way to balance the work as well as family life because teleworking enables strong family and life balance along with flexibility while lessening the environmental mobility effects.

In the literature, mixed shreds of evidence are found regarding teleworking and its associated outcomes. For instance, De Vries, Tummers and Bekkers (2019), in their study, unveiled that teleworking has a quite negative impact among public servants in the form of professional isolation and lesser commitment towards the organization, especially during the days when they worked from home. In contrast, teleworking does not affect work engagement on the other hand. Muyassarzoda, Sanjar and Gulnora (2020) found that during COVID-19 in Uzbekistan, teleworking has a positive association with labor productivity on one sideways. Contrary to this, they also revealed that teleworking has a substantial link with management complicatedness. It eventually results in the creation of a negative socioemotional environment among the work team. As per Chernozhukov, Kasahara and Schrimpf (2021), the policies adopted to prevent the spread of COVID-19 cases include social distancing behavior and wearing of face masks at public places. They postulate that in the US, the policies adopted, such as the facemask policy, have demonstrated a fruitful outcome in terms of reducing the number of COVID-19 cases on the one hand, whereas the policies related to face mask has appeared to be producing more robust outcomes than the fallouts regarding the closure of business and orders linked to stay-at-home. Similarly, measures have been taken to preserve the existing jobs and firms because of the emergence of a pandemic by the government during a lockdown. They postulate that these measures 
have largely met the goals, particularly in Europe than in the US, as explained by Blanchard, Philippon and Pisani-Ferry (2020).

In the parallel vein, the COVID-19 crisis has forced people to employ digital technologies to keep the business operation working when everyone stays at home to save their lives, while these technologies are perhaps having a long-term impact on firms for individuals concerning online shopping. At the same time, robots are used to deliver the supplies, telehealth, drones, 5G, and supply chain 4.0 have been employed to ensure the smooth functioning of business (Kamal, 2020). Therefore, the digital aspect's importance has grown across every sector of society and businesses to keep life normal during and after a pandemic. According to Riom and Sivropoulos-Valero (2020), during COVID-19 crisis, numerous firms have adopted technological innovation to foresee their operation effectively towards amplifying the firm productivity without replacing the human resources. Similarly, numerous issues exist in Romania in terms of changing professions and appearance, along with the disappearance of outdated professions due to the emergence of technology in the current scenario (Radulescu, et al., 2021). Furthermore, Stănculescu (2021) explicated that a negative link exists among resilience, happiness, and fear in Romania, particularly in the current Pandemic scenario like COVID-19. Working from home as well as teleworking is again prioritized in Romania due to strict restrictions imposed by the government as a result of the emergence of COVID-19 for employers (Nacuta, 2020).

As in the literature limited studies exist in which the link between COVID-19 policies, adoption of advanced technologies, teleworking, and firm's productivity concerning Romania's manufacturing companies is examined. Therefore, this study attempted to fill this gap. Henceforth, the objectives of our study that is put forth are to examine firstly, whether the COVID-19 pandemic is a significant cause in the increase of Teleworking. Secondly, in what way COVID-19 pandemic is a significant cause in the adoption of advanced technology. Thirdly, the COVID-19 pandemic is negatively correlated with Romanian firms' productivity. Fourth, whether the adoption of advanced technology increased the teleworking patterns. Fifth, teleworking has a significant impact on Romanian firms' productivity, and lastly, whether advanced technology has a significant impact on Romanian firms' productivity. Our study's major contribution in the existing literature is that the variables considered under the current study, i.e., COVID-19 policies, adoption of advanced technologies and teleworking, and firm's productivity concerning Romania's manufacturing companies, were not much analyzed previously in combination. However, scare studies existed in which these factors are investigated. Therefore, we have attempted to examine these factors in one study to expand the prospects regarding the Romanian manufacturing firm's productivity. The remaining part of the paper comprises the following sections: Section 2 explicates the literature related to the study variables. Besides, section 3 specifies the methodology we have adopted to collect the data, whereas Section 4 includes the findings and Section 5 contains the discussion and comparison with prior studies, and lastly, section 6 is embraced of a conclusion and practical implications.

\section{Literature Review and Hypotheses Development}

\subsection{COVID-19 Pandemic and Teleworking}

Gajendran and Harrison (2007) defined teleworking as an alternative arrangement of work to interact with others using the electronic medium or technology other than the normal 
way of doing work from the workplace. In literature, teleworking is used in terms of telecommuting, flexible work arrangement, work from home, or remote working (Abulibdeh, 2020; Groen, Van, Coers and Wtenweerde, 2018). Ollo-López, Goñi-Legaz and Erro-Garcés (2020) have demonstrated that around $20 \%$ of the employees occasionally worked outside the employer's premises until the current Pandemic COVID-19, while home-based telework percentage was lower around 5\% before that pandemic.

The term teleworking has gained momentum after the emergence of COVID-19. Accordingly, Milasi, González-Vázquez and Fernández-Macías (2021) have asserted that telework has been observed as a prevalent practice across countries due to the outbreak of COVID-19 that perhaps induced people to work from home on one side, whereas the ability to further used the telework practice in the future without hindering the level of productivity. Henceforth, teleworking policies' execution might see as an important factor for the continuity of business during COVID-19, where people cannot perform their duties at their workplace (Abulibdeh, 2020). However, telework allows employees to do their duties remotely to efficiently and effectively keep the organizational operations functioning.

In the corresponding vein, Baert, et. al (2020) also explicated that teleworking is seen as a positive aspect during the COVID-19 crisis as the execution of teleworking has resulted in increasing the efficiency among employees in order to perform their work along with lower risk linked to burnout. Therefore, across the globe people have been forced to work from home with the emergence of crises like COVID-19. During the pandemic, teleworking in terms of the provision of flexible working hours can lead to bringing positive changes related to work-life balance and good psychological health which in turn improves the work efficiency of Japanese teleworkers as well (Okubo, Inoue and Sekijima, 2021). Thus, during the spread of COVID-19, teleworking is considered a promising protective measure in order to save the employees from infection. Henceforth, the following hypothesis is developed:

\section{H1: COVID-19 pandemic is positively impact on Teleworking trends.}

\subsection{COVID-19 Pandemic and Adoption of Advanced Technology}

The Novel Strain of COVID-19 has brought severe consequences in every sector of society around the world, including the healthcare, transportation, manufacturing, and other industries together with restriction of mobility-related to people due to the implementation of quarantine policy which eventually leads to affect the economy and its associated sectors (Shen, et. al, 2020). According to Abulibdeh (2020), the technological facet allows the employees to be always connected through personal devices such as smartphones, laptops, and tablets to perform the allocated work outside their workplace. Also, deliberating to teleworking the technological aspect is a key factor for the firm higher productivity (Baruch and Nicholson, 1997). Technology has made it possible to redefine the way work is done from the traditional office to home-based or remote working (Davenport and Pearlson, 1998). The productivity of a firm can be improved by combining a diverse set of technologies as well as capabilities of data analytics that is found to be more valuable for firms that are focused on improving their processes (Wu, Hitt and Lou, 2020).

Also, Akpan, Soopramanien and Kwak (2020) and Laudon and Laudon (2019) explained in their study that the adoption of advanced technologies brings numerous benefits in terms of digitization of internal operations as well as processes which in turn results in improving 
the efficiency and effectiveness together with ensuring the survival of the business. Furthermore, in the parallel vein, Al-Maroof, et. al (2020) divulged that COVID-19 emergence increases the need to adopt technology to run the institutional operations smoothly. Moreover, Riom and Valero (2020) found that numerous firms have adopted new technologies during the period of COVID-19, which results in improving the productivity level of employees and improving the capabilities of firms.

According to De, Pandey and Pal (2020), COVID-19 has led organizations to inevitably upsurge the use of digital technology in order to manage the business operations as people and organizations had to make adjustments to the new way of working due to the restrictions imposed such as social distancing and lockdown. This argument is supported by the study of Clipper (2020) in which it is delineated as the use of technology amid the COVID-19 has upsurged and it is now viewed as an essential factor for organizations in all sectors including the healthcare setup in order to maintain the social distance, however, the work has never been stopped just because of the adoption of technology by the organization to address the needs of people This means that COVID-19 is regarded as an important element for organizations to adopt technology for the functioning of their work. Thus, the subsequent hypothesis is framed:

H2: COVID-19 pandemic is positively correlated with the adoption of advanced technology.

\subsection{COVID-19 Policies and Firm Productivity}

Governments around the globe have taken initiatives to curb the spread of COVID-19. Primarily, major strategies have been adopted to deal with this pandemic. Firstly, the nonpharmaceutical interventions like closures of schools, restriction on mass gatherings with mandatory masks wearing, and isolation of infected persons with proper disinfection (Bootsma and Ferguson, 2007; Cowling and Aiello, 2020). Secondly, COVID-19 policies have been implemented by the government in response to control the influence of deadly virus across the globe through the closure of borders via travel bans as well as restricting the movement of people from one place to another place in the form of lockdown, wearing of a mask, and urging people to work from home along with the closure of markets and businesses with provision of support to people and businesses by a government who lost their jobs in this pandemic (Gourinchas, 2020; Narayan, Phan and Liu, 2021; O'Neill, 2020; Piguillem and Shi, 2020).

Viewing from the firm-level perspective, the COVID-19 pandemics adversely affect the stock market (Hanspal, Weber and Wohlfart, 2020; Njindan, 2020) and drop in sales (Bloom, Fletcher and Yeh, 2021). Accordingly, COVID-19 policies have primarily affected all organizations including small-medium enterprises as well. This pandemic might perhaps have a long-lasting effect on the productivity of the firm as the indebtedness along with the presence of uncertainty may lead to inhibit the investments together with that closure of firms which eventually stakes the existence and productivity of firms (De Nicola, et al., 2021).

Shen, et al. (2020) conducted a study using Chinese companies' financial data regarding the COVID-19 and corporate productivity. They unveiled that COVID-19 negatively impacts corporate productivity because of small sales revenues and investments. Furthermore, Fu and Shen (2020) also unveiled similar results that COVID-19 negatively affects energy companies' productivity. On the opposing side, Kozeniauskas, Moreira and Santos (2020) 
found that the shock due to the COVID-19 is of varying degrees across Portuguese firms as numerous firms experienced sales declines, firms with high productivity were remained open with less support of the government. Consequently, we have framed the following hypothesis based on the above-mentioned arguments:

H3: COVID-19 pandemic is negatively correlated with Romanian firms' productivity.

\subsection{Adoption of Advanced Technology and Teleworking}

Teleworking might bring benefits for employees as well as for firms. For instance, from the employee perspective, teleworking helps create a balance between work and family, career advancements, transportation, and commuting cost reduction. In contrast, telework can increase productivity from the firm perspective, particularly in the pandemic (COVID-19) situation, by attracting and retaining the workers and reducing the cost linked to office space (Ollo-López, et al., 2020). Accordingly, for organizations teleworking brings numerous benefits in reducing overhead cost, increased competitive advantage, and efficiencies at the organizational level (Gill, 2006).

In line with this argument, telework is a form of flexible work arrangement that helps employees fulfill their activities with technology support (De Vries, et al., 2019). On the other side, teleworking is considered an easy way to adopt in order to fulfill the assigned duties yet it can be difficult for professionals without having proper infrastructure as well as resources like internet availability and management of time to work from home (Tavares, et al., 2020). As per the arguments, this means that technology is the main aspect of teleworking as it can permit more freedom to work from anywhere. Henceforth, the availability of the internet is seen as the base for teleworking along with the evolution of technological tools to bring ease and efficiency in the life of a worker on one hand, whereas the availability of the internet connection might result in improving the connectivity and communication with the organization which in turn produce more fruitful results (Pearce, 2009; Bucşa, 2020). Moreover, Grigorescu and Nicolae (2020) technology has been adopted by organizations to allow people to work from home, and it has now become a part of the work around the globe during this pandemic. This means that firms have adopted technology to bring ease to employees' lives through this period and resulted in the boost of teleworking. Therefore, we have framed the following hypothesis for our study:

\section{H4: Adoption of advanced technology increased the teleworking patterns.}

\subsection{Teleworking and Firm Productivity}

Technology helped produce greater flexibility, productivity, and effectiveness in work during the transformation from traditional office working to teleworking (Baruch, 2000). Also, Kim, Mullins and Yoon (2021) posits that an organization having telework arrangements might improve an organization's productivity when supervision is based on results and trust-building efforts. Similarly, Bai, et al. (2021) have avowed that availability of opportunities in the firm for employees during COVID-19 in terms of working from home can bring more safety for employees whereas work from home practices facilitate firms to cope with foremost adverse shocks at the social and economic levels. So, based on shreds of evidence it depicts that work from home is seen as an important facet for the continuation of firm operations and activities. Correspondingly, Giovanis (2018) also explained in their study the execution of flexible working arrangements could have a positive relationship with workplace productivity in Great Britain. Moreover, the link 
between attitude towards teleworking and perceived productivity has a weak relationship (Kasemsukprakarn and Dowpiset, 2020). This means that when the employee has a positive attitude, it might improve the productivity level.

H5: Teleworking has a positive and significant impact on Romanian firms' productivity.

\subsection{Adoption of technology and Firm Productivity}

In the era of continuous changes, firms have been more concerned about maintaining their productivity to sustain competitive advantage. Akpan, Udoh and Adebisi (2020) have shared a view that adoption of technologies like cloud computing, the internet of things, data analytics are viewed as an important strategy to gain a competitive advantage during COVID-19 and, henceforth, successful adoption of advanced technologies is a key aspect of surviving after COVID-19. Mainly, when viewing the productivity of firms nowadays, firms have been adopting the paradigms of different technological facets, including web 2.0 and social media (Jussila, Kärkkäinen and Aramo-Immonen, 2014), execution of artificial intelligence (Duan, Edwards and Dwivedi, 2019; Zeng, et al., 2010) and blockchain technology (Dubey, et al., 2020).

While the execution of new technologies results in improving the businesses by amplifying the customer experience and optimizing operations (Warner and Wäger, 2019), besides, Lin, et al. (2020) affirmed that investments by firms to adopt the information technologies have been demonstrating a noteworthy role in bringing innovation via improving the processes towards catering to their customers accordingly. Furthermore, Yadegaridehkordi et al. (2018) also avowed that technological resources, quality of big data, and integration have a greater impact on the adoption of big data and the firm's productivity.

Contrary to this, Alekseeva, et al. (2020) showed a positive relationship between firm-level adoption of artificial intelligence, size of the firm, research and development, Capex, and total investments, whereas no strong association exists with measures of productivity. In the same vein, technology adoption is an important factor for the firm productivity and proper management of resources. Further, the absorptive capability is eventually regarded as a crucial aspect for effective adoption of technology (Arifin, Firmanzah and Fontana, 2015). Accordingly, John, James and Scott (1998) also shared the parallel views that adoption of innovation at a technological level perhaps lead to augment the productivity of firms in the service sector on one side, whereas failure to adopt might lead to affect the firm image negatively in terms of catering the customers effectively. Similarly, Lin et al. (2020) found that technology adoption positively influences the firm's productivity, in which leadership plays a vital role. Therefore, we have developed the following hypotheses based on the existing literature:

H6: Advanced technology has a positive and significant impact on Romanian firms' productivity.

\subsection{Proposed Model of the Study}

The proposed model of our study is indicated in figure 1, containing predictors as well as outcome variables. 


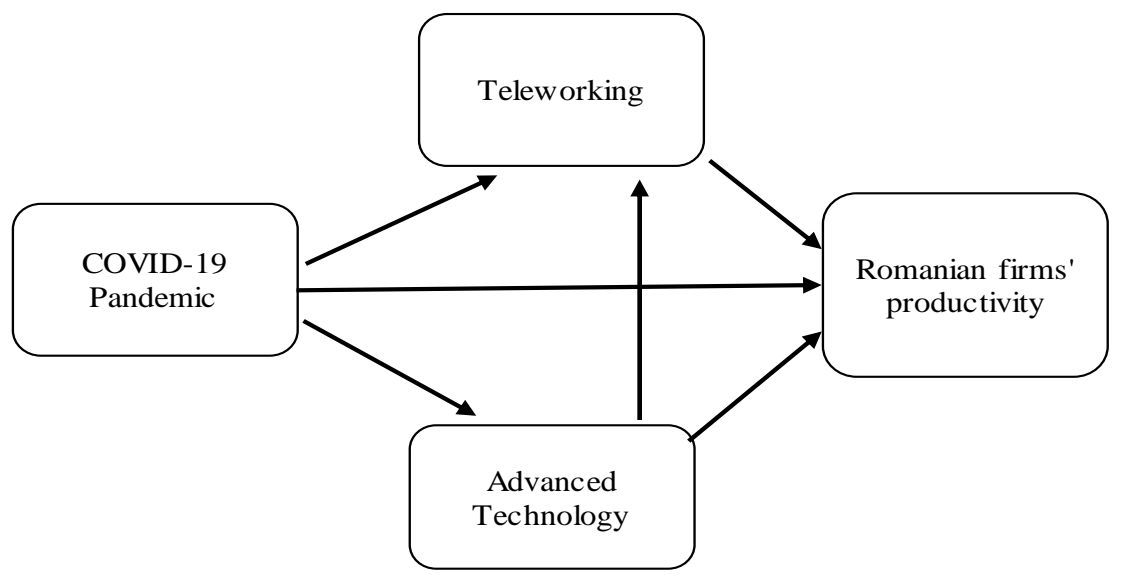

Figure no. 1. Proposed model

\section{Research Methodology}

The data in the study was collected from a sample of 328 respondents including the Vice President, Operation Manager, General manager, Logistics Manager, Procurement Manager, and Information system manager. The responses were collected from employees working in different setups such as Chemical manufacturer, Metal product manufacturer, electronic products, Artificial leather-related products, Transportation equipment manufacturer, Paper manufacturer, Textile, and clothing as well as Plastic and rubber manufacturer operating in Romania.

In our study, convergent validity was measured through the factor loading as specified by (Jaya, Hermina and Sunengsih, 2019). Furthermore, to assess the convergent validity, the average variance extracted (AVE) value has been observed, the criteria recommended by Fornell and Larcker (1981). Discriminant validity was assessed using Fornell Larcker criteria and cross-loadings (Henseler, Ringle and Sinkovics, 2009). CB-SEM is used to develop a covariance (theoretical) matrix built on a specified set of structural equations. The reason for choosing this technique is that as it helps to assess the difference between theoretical and covariance matrix whereas the estimated covariance matrix is minimized as projected by Hair, Ringle and Sarstedt (2011) and Rigdon (2012). Moreover, Hair et al. (2011) explicated that CB SEM is regarded as an important technique when the objective of the research is testing of theory along with its confirmation, whereas when the objective of the research is a development of theory and prediction, then PLS-SEM is viewed as an appreciated technique to employ. Furthermore, the rule of thumb to employ CB SEM versus PLS-SEM is demonstrated as: Firstly, the rule for choosing CB SEM is theory testing, while error terms need supplementary specification, such as the covariation whereas structural model has circular relationships, and the research necessitates global goodness of fit criterion. On the other side, PLS-SEM specifies via predicting key target constructs, formative measures, the complex structural model, small sample size, and the non-normally distributed data and use of latent variable scores in succeeding analyses (Hair et al., 2011). 


\section{Results}

\subsection{Demographic Profile}

The demographic profile of respondents is specified in table 1. Firstly, as far as job titles are concerned, $31.4 \%$ of respondents were the operation manager, $24.7 \%$ were the logistics manager, $17.1 \%$ were the information system manager, $14.0 \%$ were the general manager, $8.8 \%$ were the procurement manager, and $4.0 \%$ were the Vice presidents. Moreover, conferring to the job experience, the highest $\%$ of people, i.e., $34.5 \%$, were the people with 5-10 years of experience, whereas the lowest ones, i.e., 5.8\% the people having the experience of over 20 years. Besides, most respondents, i.e., 20.7\%, belong to plastic and rubber manufacturers, whereas on the lower side, i.e., $7.0 \%$ to the chemical manufacturer and artificial leather-related products, respectively.

Table no. 1. Demographic Profile

\begin{tabular}{lll}
\hline Characteristics & N & \% \\
\hline Job title & 13 & 4.0 \\
\hline Vice President & 103 & 31.4 \\
\hline Operation manager & 46 & 14.0 \\
\hline General manager & 81 & 24.7 \\
\hline Logistics manager & 29 & 8.8 \\
\hline Procurement manager & 56 & 17.1 \\
\hline Information system manager & & \\
\hline Job Experience & 43 & 13.1 \\
\hline Less than 5 & 113 & 34.5 \\
\hline 5 to 10 & 89 & 27.1 \\
\hline 10 to 15 & 64 & 19.5 \\
\hline 15 to 20 & 19 & 5.8 \\
\hline Over 20 years & & \\
\hline Industry & 23 & 7.0 \\
\hline Chemical manufacturer & 61 & 18.6 \\
\hline Metal product manufacturer & 42 & 12.8 \\
\hline Electronic products & 23 & 7.0 \\
\hline Artificial leather related products & 27 & 8.2 \\
\hline Transportation equipment manufacturer & 33 & 10.1 \\
\hline Paper manufacturer & 51 & 15.5 \\
\hline Textile and clothing & 68 & 20.7 \\
\hline Plastic and rubber manufacturer & & \\
\hline
\end{tabular}




\subsection{Convergent Validity}

Table 2 specifies the convergent validity of the research instrument. The factor loading of all constructs is greater than 0.7, which falls within the specified criteria (Jaya, Hermina and Sunengsih, 2019). While the instrument's reliability is also greater than 0.70 , which again meets the criteria as specified by Hair et al., (2011). Furthermore, to assess the convergent validity, the average variance extracted (AVE) value have been observed and the result depicts that the value of AVE is greater than 0.5, this means that there is no issue of convergent validity as the value meets the criteria recommended by Fornell and Larcker (1981).

Table no. 2. Convergent Validity

\begin{tabular}{|c|c|c|c|c|c|}
\hline Variables & Indicator & Factor Loading & Cronbach's $\alpha$ & $\mathbf{C R}$ & AVE \\
\hline \multicolumn{6}{|c|}{ COVID-19 Pandemic } \\
\hline \multirow{2}{*}{$\begin{array}{l}\text { Personal perceived } \\
\text { risk (aa1) }\end{array}$} & a1 & 0.782 & \multirow[t]{2}{*}{0.854} & \multirow[t]{2}{*}{0.862} & \multirow[t]{2}{*}{0.632} \\
\hline & a3 & 0.846 & & & \\
\hline \multirow[t]{2}{*}{ Policies (aa2) } & $\mathrm{a} 4$ & 0.916 & \multirow[t]{2}{*}{0.916} & \multirow[t]{2}{*}{0.918} & \multirow[t]{2}{*}{0.833} \\
\hline & a5 & 0.917 & & & \\
\hline \multicolumn{6}{|c|}{ Teleworking } \\
\hline \multirow[t]{2}{*}{ Flexibility (bb1) } & $\mathrm{bb} 1$ & 0.872 & \multirow[t]{2}{*}{0.931} & \multirow[t]{2}{*}{0.924} & \multirow[t]{2}{*}{0.73} \\
\hline & bb2 & 0.916 & & & \\
\hline \multirow[t]{2}{*}{ Satisfaction (bb2) } & bb3 & 0.821 & \multirow[t]{2}{*}{0.888} & \multirow[t]{2}{*}{0.902} & \multirow[t]{2}{*}{0.712} \\
\hline & bb4 & 0.829 & & & \\
\hline \multicolumn{6}{|c|}{ Advanced Technology } \\
\hline \multirow{5}{*}{$\begin{array}{l}\text { Information } \\
\text { sharing ability } \\
\text { (cc1) }\end{array}$} & $\operatorname{cc1}$ & 0.843 & \multirow[t]{5}{*}{0.832} & \multirow[t]{5}{*}{0.816} & \multirow[t]{5}{*}{0.629} \\
\hline & $\operatorname{cc} 2$ & 0.878 & & & \\
\hline & $\operatorname{cc} 4$ & 0.837 & & & \\
\hline & $\operatorname{cc6}$ & 0.869 & & & \\
\hline & $\operatorname{cc} 7$ & 0.852 & & & \\
\hline \multirow{3}{*}{$\begin{array}{l}\text { Coordination } \\
\text { ability (cc2) }\end{array}$} & $\operatorname{cc} 10$ & 0.821 & \multirow[t]{3}{*}{0.867} & \multirow[t]{3}{*}{0.883} & \multirow[t]{3}{*}{0.77} \\
\hline & $\mathrm{cc} 12$ & 0.849 & & & \\
\hline & $\operatorname{cc} 13$ & 0.797 & & & \\
\hline \multirow{4}{*}{$\begin{array}{l}\text { Integration ability } \\
\text { (cc3) }\end{array}$} & $\operatorname{cc} 15$ & 0.856 & \multirow[t]{3}{*}{0.793} & \multirow[t]{3}{*}{0.857} & \multirow[t]{3}{*}{0.738} \\
\hline & $\operatorname{cc} 16$ & 0.858 & & & \\
\hline & cc18 & 0.941 & & & \\
\hline & \multicolumn{2}{|c|}{$\begin{array}{c}\text { Romanian Firms' } \\
\text { Productivity }\end{array}$} & & & \\
\hline Reduction in & ee1 & 0.881 & 0.847 & 0.858 & 0.714 \\
\hline expenses (dd1) & ee2 & 0.862 & & & \\
\hline Profitability (dd2) & ee3 & 0.841 & 0.859 & 0.778 & 0.692 \\
\hline & ee4 & 0.797 & & & \\
\hline
\end{tabular}

\subsection{Discriminant Validity}

Table 3 indicates the discriminant validity of the research instrument. Discriminant validity can be assessed using Fornell Larcker criteria and cross-loadings (Henseler, Ringle and Sinkovics, 2009). In our study, Fornell Larcker criteria were used for assessment. According to Fornell and Larcker (1981), the value of AVE of each construct must be greater than the squared correlation among all the constructs. The outcome's discriminant 
validity is confirmed for our model as the square root of each construct's AVE is greater than its correlation with other constructs.

Table no. 3. Discriminant validity

\begin{tabular}{llllllllll}
\hline & bb1 & bb2 & cc1 & $c c 2$ & $c c 3$ & dd1 & dd2 & aa1 & aa2 \\
\hline bb1 & $\mathbf{0 . 8 0 3}$ & & & & & & & & \\
\hline bb2 & 0.601 & $\mathbf{0 . 8 1 6}$ & & & & & & & \\
\hline cc1 & 0.497 & 0.661 & $\mathbf{0 . 8 3 9}$ & & & & & & \\
\hline cc2 & 0.546 & 0.623 & 0.796 & $\mathbf{0 . 6 6 3}$ & & & & & \\
\hline cc3 & 0.535 & 0.681 & 0.792 & 0.656 & $\mathbf{0 . 8 2 3}$ & & & & \\
\hline dd1 & 0.633 & 0.555 & 0.629 & 0.545 & 0.769 & $\mathbf{0 . 8 3 2}$ & & & \\
\hline dd2 & 0.482 & 0.593 & 0.571 & 0.603 & 0.742 & 0.781 & $\mathbf{0 . 7 6 2}$ & & \\
\hline aa1 & 0.372 & 0.668 & 0.420 & 0.496 & 0.582 & 0.702 & 0.529 & $\mathbf{0 . 8 7 9}$ & \\
\hline aa2 & 0.389 & 0.535 & 0.493 & 0.483 & 0.627 & 0.375 & 0.567 & 0.795 & $\mathbf{0 . 7 7 5}$ \\
\hline
\end{tabular}

\subsection{Goodness of Fit of Structural Equation Model}

The goodness of Fit of Structural Equation Model is depicted in table 4. All the criteria's meets the specified value, which shows the measurement model fit with the data in our study, such as the value of RMSEA $=0.0519$, which is less than 0.08 , while the value of chisquare $=2.521$ which is $<3$, the value of NFI $=0.929$ which is less than 0.929 , and lastly the value of TLI $=0.938$ which is again $>0.90$.

Table no. 4. Goodness-of-fit of structural equation model

\begin{tabular}{llllllll} 
Fit Index & $\chi 2 / \mathbf{d f}$ & RMSEA & GFI & AGFI & NFI & TLI & CFI \\
\hline $\begin{array}{l}\text { Recommended } \\
\text { criteria }\end{array}$ & $<3$ & $<0.08$ & $>0.9$ & $>0.80$ & $>0.90$ & $>0.90$ & $>0.90$ \\
\hline Model results & 2.521 & 0.0519 & 0.918 & 0.841 & 0.929 & 0.938 & 0.931 \\
\hline
\end{tabular}

\subsection{Hypotheses Testing}

Table 5 indicates the estimation of the structural model. Out of six hypotheses, five hypotheses are accepted. Referring to hypothesis 1- The COVID-19 pandemic is a significant cause of Teleworking's increase is accepted as beta value is 0.611 and p-value is 0.000. While hypothesis 2- COVID-19 pandemic is a significant cause in adopting advanced technology, it is not accepted as the value of beta is 0.652 and p-value are 0.841 . Moreover, hypothesis 3- COVID-19 pandemic is negatively correlated with Romanian firms' productivity is accepted as beta value is -0.184 and p-value is 0.039 . Besides, hypothesis 4 - the adoption of advanced technology increased to the teleworking patterns is accepted as beta value is 0.562 and p-value is 0.000 . In addition, hypothesis 5- teleworking has a positive and significant impact on Romanian firms' productivity is accepted as beta value is 0.612 and p-value is 0.000 , and hypothesis 6 - advanced technology have a positive 
and significant impact on Romanian firms' productivity is accepted as value of beta is 0.524 and p-value is 0.025 . Figure 2 indicates the SEM Model results.

Table no. 5. Standardized parameter estimates for a structural model

\begin{tabular}{llllll}
\hline $\begin{array}{l}\text { Hypot } \\
\text { hesis }\end{array}$ & Paths & & $\begin{array}{l}\text { Standardized } \\
\text { estimate }\end{array}$ & P-value & Results \\
\hline H1 & COVID-19 $\rightarrow$ Teleworking & $0.611^{* *}$ & 0.000 & Supported \\
\hline H2 & COVID-19 $\rightarrow$ Adv.Tech & 0.652 & 0.841 & Not Supported \\
\hline H3 & COVID-19 $\rightarrow$ Romanian F. P & $-0.184^{*}$ & 0.039 & Supported \\
\hline H4 & Adv. Tech $\rightarrow$ Teleworking & $0.562^{* *}$ & 0.000 & Supported \\
\hline H5 & Teleworking $\rightarrow$ Romanian F. P & $0.612^{* *}$ & 0.000 & Supported \\
\hline H6 & Adv. Tech $\rightarrow$ Romanian F. P & $0.524^{*}$ & 0.025 & Supported \\
\hline Note: $* *$ and $*$ indicate significance at 1\% and 5\% respectively. & & \\
\hline
\end{tabular}

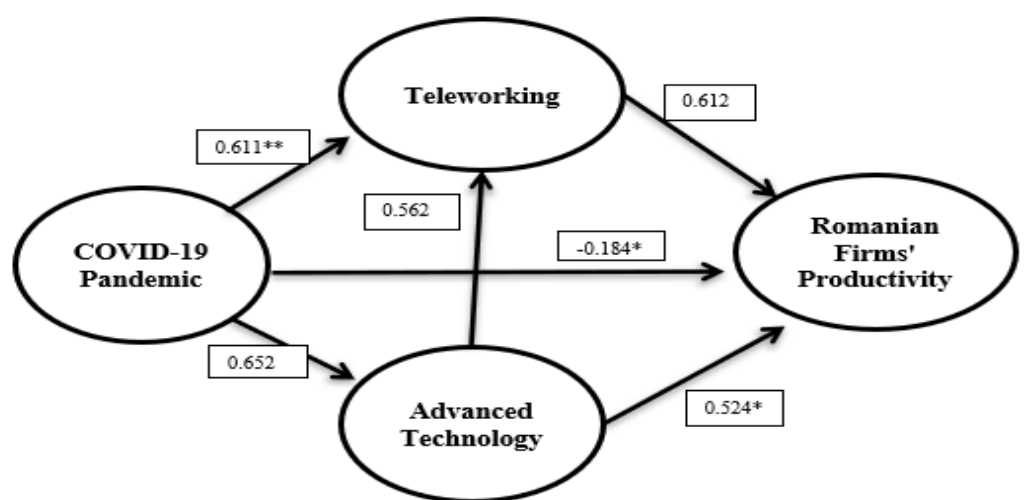

Figure no. 2. SEM Model results

\section{Discussion}

We have attempted to conduct a study to examine the impact of COVID-19 policies, the adoption of advanced technology, and teleworking on firm productivity in Romania. After analyzing the collected data, we have found that the COVID-19 pandemic has a significant effect in increasing the Teleworking practices in Romania. While the results are in line with the literature, teleworking has been observed as a prevalent practice across countries due to the outbreak of COVID-19 that perhaps induced people to work from home (Milasi, et al., 2021). Henceforth, teleworking is seen as an important factor for business continuity during COVID-19 (Abulibdeh, 2020). Moreover, hypothesis 2 is that the COVID-19 pandemic is a significant cause in the adoption of advanced technology is not accepted. This means that COVID-19 is not the prime factor related to the adoption of advanced technology as firms have already intricate to adopt new technology, and this argument is consistent with the argument of Jussila et al. (2014) that firms have been adopting the paradigms of different technological facets to improve their productivity. 
Correspondingly, the COVID-19 pandemic is negatively correlated with Romanian firms' productivity is accepted. This means that the emergence of COVID-19 affects the firm's productivity negatively. These results are consistent with studies conducted by Shen et al. (2020) and Fu \& Shen (2020). Moreover, hypothesis 4 - Adoption of advanced technology increased to the teleworking patterns is accepted. The results are per current literature (Abulibdeh, 2020) and (De Vries et al., 2019). Similarly, technology helps produce greater flexibility, productivity, and effectiveness in teleworking (Baruch, 2000). Besides, hypothesis 5- Teleworking has a positive and significant impact on Romanian firms' productivity is accepted. Our study results are in line with the outcomes of studies conducted by Kim et al. (2021); Ollo-López et al. (2020) and Giovanis (2018). Contrary to this, Kasemsukprakarn and Dowpiset (2020) explicated that employee having a positive attitude might lead to improving the productivity level along with that a weak positive link exists related to commitment towards organization and productivity-related to teleworking and hypothesis 6- Advanced technology has a positive and significant impact on Romanian firms' productivity is accepted. The results are consistent with the studies of Arifin et al. (2015); Irwin et al. (1998); Lin et al. (2020), whereas the results are not in line with the outcomes of Alekseeva et al. (2020).

\section{Conclusion and Implications}

The main purpose of our study was to inspect the impact of COVID-19 policies, the adoption of advanced technology, and teleworking on firm productivity in Romania. Our study presented an empirical result regarding the COVID-19 Policies, adoption of Advanced technology, teleworking, and firm productivity by using a sample of 328 and analyzing it through the CB SEM technique. Contrary to prior approaches, our study employed the CE SEM technique to test the theory which is viewed as a methodological contribution to teleworking literature. As per the outcomes, the COVID-19 pandemic plays a huge role in increasing teleworking practices in Romania, while the COVID-19 pandemic is not viewed as a significant cause in the adoption of advanced technology in Romania. While this pandemic negatively affects Romania's firm productivity, whereas teleworking and adoption of advanced technology positively affect the Romanian firms' productivity, and lastly, the adoption of advanced technology helps increase the pattern of teleworking easier in Romania. We have concluded that the emergence of COVID-19 has drastically transformed the way people are working along with that the productivity of firms also varies due to this catastrophic event that happened at the end of the year 2019.

Primarily, COVID-19 has influenced businesses, people, society, and the economy as a whole. Numerous organizations close to prevent disease, people stay at home and start working from home in various countries including Romania. So, the increased use of teleworking practices has been an important practice in Romania to follow the COVID-19 policies imposed by the government on one side, yet to keep the business ongoing by working from home via employing the technology in order to maintain the firm productivity on other hand. As COVID-19 is not stopped here, there are some implications for firms that need to be considered by the Romanian government to boost the economy. Firstly, firms need to encourage people to effectively use the technology in order to perform their duties on time from sitting at their home on one side whereas Government must provide proper infrastructure and technological tools to the firms in order to save employees and firms' well-being. Secondly, collaboration with the international community 
can help them regarding the development of policies to involve more users to aid in adopting technologies in Romania. Thirdly, the adoption of advanced technology also led to help in facing the challenges that emerge during and post-COVID-19 situations for the handling of employees and firm productivity effectively. Fourth, the use of teleworking during and post-COVID 19 might perhaps need planning from the perspective of dealing with anticipated health catastrophes to save the life of employees on one side and firm productivity on the other end. Teleworking may not be treated as an occasional measure derived from catastrophes arise from health or environmental aspect yet must be taken as a strategy for cost reduction related to infrastructure as well as to shape the favorable climate at the workplace for ensuring work and family life balance. Once this pandemic is over, the Romania firms may offer the options to their employees to continue teleworking or may resume their presence at the workplace as this will be the new issue that may arise after the pandemic for firms. Therefore, strategies need to be developed to handle this issue.

This study has few limitations: firstly, this study is confined to Romanian firms only; future studies must conduct this study in other developing countries. Secondly, a small size was used; future researchers may employ a large sample size to see the effects and further expand the horizon.

\section{Acknowledgement}

This research is supported by Beijing Key Laboratory of Urban Spatial Information Engineering (NO. 20210218) and National Natural Science Foundation of China (No. 202202457).

\section{Reference}

Abulibdeh, A., 2020. Can COVID-19 mitigation measures promote telework practices? Journal of Labor and Society, 23(4), pp.551-576. https://doi.org/10.1111/wusa.12498.

Akpan, I.J., Soopramanien, D. and Kwak, D.-H., 2020. Cutting-edge technologies for small business and innovation in the era of COVID-19 global health pandemic. Journal of Small Business \& Entrepreneurship, pp.1-11. https://doi.org/10.1080/ 08276331.2020 .1799294$.

Akpan, I.J., Udoh, E.A.P. and Adebisi, B., 2020. Small business awareness and adoption of state-of-the-art technologies in emerging and developing markets, and lessons from the COVID-19 pandemic. Journal of Small Business \& Entrepreneurship, pp.1-18. https://doi.org/10.1080/08276331.2020.1820185.

Al-Maroof, R.S., Salloum, S.A., Hassanien, A.E. and Shaalan, K., 2020. Fear from COVID-19 and technology adoption: the impact of Google Meet during Coronavirus pandemic. Interactive Learning Environments, pp.1-16. https://doi.org/10.1080/ 10494820.2020.1830121.

Alekseeva, L., Gine, M., Samila, S. and Taska, B., 2020. AI Adoption and Firm Performance: Management versus IT.SSRN Electronic Journal. [online] https://doi.org/10.2139/ssrn.3677237. 
Anon., 2020. Productivity gains from teleworking in the post COVID-19 era: How can public policies make it happen? (OECD Policy Responses to Coronavirus (COVID-19)). (2020). pp.1-24. Paris: OECD. https://doi.org/10.1787/a5d52e99-en.

Arifin, Z.F. and Fontana, A., 2015. The determinant factors of technology adoption for improving a firm's performance. Paper presented at the International Symposium on Technology Management and Emerging Technologies (ISTMET), pp.181-186.

Baert, S., Lippens, L., Moens, E., Weytjens, J. and Sterkens, P., 2020. The COVID-19 crisis and telework: A research survey on experiences, expectations and hopes. IZA Institute of Labor Economics, pp.1-37.

Bai, J.J., Brynjolfsson, E., Jin, W., Steffen, S. and Wan, C., 2021. Digital Resilience: How Work-From-Home Feasibility Affects Firm Performance. [pdf] National Bureau of Economic Research. Available at: <https://siepr.stanford.edu/sites/default/files/ publications/21-016.pdf> [Accessed 20 February 2021].

Baruch, Y. and Nicholson, N., 1997. Home, Sweet Work: Requirements for Effective Home Working. Journal of General Management, 23, pp.15-30.

Baruch, Y., 2000. Teleworking: Benefits and pitfalls as perceived by professionals and managers. New Technology, Work and Employment, 15(1), pp.34-49. https://doi.org/10.1111/1468-005X.00063.

Belzunegui-Eraso, A. and Erro-Garcés, A., 2020. Teleworking in the Context of the COVID-19 Crisis. Sustainability, 12(9), pp.3662.

Blanchard, O., Philippon, T. and Pisani-Ferry, J., 2020. A new policy toolkit is needed as countries exit COVID-19 lockdowns. Policy Contribution 12/2020, Bruegel, pp.1-14.

Bootsma, M.C.J. and Ferguson, N.M., 2007. The effect of public health measures on the 1918 influenza pandemic in U.S. cities. Proceedings of the National Academy of Sciences, 104(18), pp.7588-7593. https://doi.org/10.1073/pnas.0611071104.

Bucşa, R.-C., 2020. Teleworking and Securing Data with VPN Technology. Economy Transdisciplinarity Cognition, 23(1), pp.78-85.

Chernozhukov, V., Kasahara, H. and Schrimpf, P., 2021. Causal impact of masks, policies, behavior on early COVID-19 pandemic in the US. Journal of Econometrics, 220(1), pp.23-62.

Clipper, B., 2020. The influence of the COVID-19 pandemic on technology: adoption in health care. Nurse Leader, 18(5), pp.500-503.

Cowling, B.J. and Aiello, A.E., 2020. Public health measures to slow community spread of coronavirus disease 2019. The Journal of infectious diseases, 221(11), pp.1749-1751.

Davenport, T.H. and Pearlson, K., 1998. Two cheers for the virtual office. MIT Sloan Management Review, 39, pp.51-65.

De Nicola, F., Mattoo, A., Timmis, J. and Tran, T.T., 2021. Productivity in the Time of COVID-19. Research \& Policy Briefs, pp.1-5.

De Vries, H., Tummers, L. and Bekkers, V., 2019. The benefits of teleworking in the public sector: Reality or rhetoric? Review of Public Personnel Administration, 39(4), pp.570-593.

De, R., Pandey, N. and Pal, A., 2020. Impact of digital surge during COVID-19 pandemic: A viewpoint on research and practice. International Journal of Information Management, 55, pp.102171. 
Duan, Y., Edwards, J.S. and Dwivedi, Y.K., 2019. Artificial intelligence for decision making in the era of Big Data-evolution, challenges and research agenda. International Journal of Information Management, 48, pp.63-71.

Dubey, R., Gunasekaran, A., Bryde, D.J., Dwivedi, Y.K. and Papadopoulos, T., 2020. Blockchain technology for enhancing swift-trust, collaboration and resilience within a humanitarian supply chain setting. International Journal of Production Research, 58(11), pp.3381-3398.

Fornell, C. and Larcker, D.F., 1981. Evaluating structural equation models with unobservable variables and measurement error. Journal of marketing research, 18(1), pp.39-50.

Fu, M. and Shen, H., 2020. COVID-19 and corporate performance in the energy industry. Energy Research Letters, 1(1), pp.12967.

Gajendran, R.S. and Harrison, D.A., 2007. The good, the bad, and the unknown about telecommuting: meta-analysis of psychological mediators and individual consequences. Journal of Applied Psychology, 92(6), pp.1524-1541. doi:10.1037/0021-9010.92.6.1524.

Gourinchas, P.-O., 2020. Flattening the pandemic and recession curves. [online] Available at: <https://voxeu.org/article/flattening-pandemic-and-recession-curves> [Accessed 22 February 2021].

Grigorescu, A. and Nicolae, A.M., 2020. Teleworking perspectives for Romanian SMEs after the COVID-19 pandemic. Management Dynamics in the Knowledge Economy, 8(4), pp.383-399.

Groen, B.A., Van Triest, S.P., Coers, M. and Wtenweerde, N., 2018. Managing flexible work arrangements: Teleworking and output controls. European Management Journal, 36(6), pp.727-735.

Hair, J.F., Ringle, C.M. and Sarstedt, M., 2011. PLS-SEM: Indeed a Silver Bullet. Journal of Marketing Theory and Practice, 19(2), pp.139-152. doi: 10.2753/MTP10696679190202.

Hanspal, T., Weber, A. and Wohlfart, J., 2020. Exposure to the COVID-19 Stock Market Crash and its Effect on Household Expectations. [SSRN Scholarly Paper] Rochester, NY: Social Science Research Network. Available at: <https://papers.ssrn.com/ abstract $=3577217>$ [Accessed 4 April 2021].

Henseler, J., Ringle, C.M. and Sinkovics, R.R., 2009. The use of partial least squares path modeling in international marketing. In: R.R. Sinkovics and P.N. Ghauri, eds. Advances in International Marketing. [online] Emerald Group Publishing Limited. pp.277-319. https://doi.org/10.1108/S1474-7979(2009)0000020014.

Irwin, J.G., Hoffman, J.J. and Geiger, S.W., 1998. The effect of technological adoption on organizational performance: organizational size and environmental munificence as moderators. The International Journal of Organizational Analysis, 6(1), pp.50-64. https://doi.org/10.1108/eb028878.

Jaya, G.N.M., Hermina, N. and Sunengsih, N., 2019. CB-SEM and VB-SEM: Evaluating Measurement model of Business Strategy of Internet Industry in Indonesia. International Journal of Scientific \& Engineering Research, 10(10), pp.878-883. 
Jussila, J.J., Kärkkäinen, H. and Aramo-Immonen, H., 2014. Social media utilization in business-to-business relationships of technology industry firms. Computers in Human Behavior, 30, pp.606-613. doi: https://doi.org/10.1016/j.chb.2013.07.047.

Kamal, M.M., 2020. The triple-edged sword of COVID-19: understanding the use of digital technologies and the impact of productive, disruptive, and destructive nature of the pandemic. Information Systems Management, 37(4), pp.310-317.

Kasemsukprakarn, J. and Dowpiset, K., 2020. A Study of Factors Relating to Perceived Teleworking Productivity of Telework Employees in Co-Working Space at Pathumwan Area and Watthana Area in Bangkok, Thailand. Raja park Journal, 14(32), pp.223-237.

Kim, T., Mullins, L.B. and Yoon, T., 2021. Supervision of Telework: A Key to Organizational Performance. The American Review of Public Administration, 51(4), pp.263-277. https://doi.org/10.1177/0275074021992058.

Kozeniauskas, N., Moreira, P. and Santos, C., 2020. Covid-19 and Firms: Productivity and Government Policies. Centre for Economic Policy Research, UK, pp.15156.

Lin, W.L., Yip, N., Ho, J.A. and Sambasivan, M., 2020. The adoption of technological innovations in a B2B context and its impact on firm performance: An ethical leadership perspective. Industrial Marketing Management, 89, pp.61-71. https://doi.org/ 10.1016/j.indmarman.2019.12.009.

Milasi, S., González-Vázquez, I. and Fernández-Macías, E., 2021. Telework before the COVID-19 pandemic: Trends and drivers of differences across the EU. OECD Productivity Working Papers, 2021-21, pp.1-18. OECD Publishing, Paris. https://doi.org/10.1787/d5e42dd1-en.

Muyassarzoda, F., Sanjar, G. and Gulnora, A., 2020. Assessing the impact of teleworking on employees' labor productivity and effectiveness of entity in the period of COVID-19. Emerging Markets Finance and Trade, 1(2), pp.35-52.

Nacuta, D., 2020. Romania: Coronavirus - New COVID-19 employment-related regulations: Latest developments. [online] Lexology. Available at: <https://www.lexology.com/library/detail.aspx?g=c50e9f27-1e21-4dce-9f8868a40ababfbe> [Accessed 12 February 2021].

Narayan, P.K., Phan, D.H.B. and Liu, G., 2021. COVID-19 lockdowns, stimulus packages, travel bans, and stock returns. Finance Research Letters, 38, pp.101732.

Njindan, I., Bernard., 2020. The disease outbreak channel of exchange rate return predictability: Evidence from COVID-19. Emerging Markets Finance and Trade, 56(10), pp.2277-2297.

O'Neill, R., 2020. WHO knew? How the World Health Organization (WHO) became a dangerous interloper on workplace health and safety and COVID-19. NEW SOLUTIONS: A Journal of Environmental and Occupational Health Policy, 30(3), pp.237-248.

Okubo, T., Inoue, A. and Sekijima, K., 2021. Teleworker performance in the COVID-19 era in Japan. Asian Economic Papers, 20(2), pp.175-192.

Ollo-López, A., Goñi-Legaz, S. and Erro-Garcés, A., 2021. Home-based telework: usefulness and facilitators. International Journal of Manpower, 42(4), pp.644-660. https://doi.org/10.1108/IJM-02-2020-0062. 
Pearce, J.A., 2009. Successful corporate telecommuting with technology considerations for late adopters. Organizational Dynamics, 38(1), pp.16-25. doi:10.1016/ j.orgdyn.2008.10.002.

Piguillem, F. and Shi, L., 2020. Optimal COVID-19 quarantine and testing policies. Einaudi Institute for Economics and Finance (EIEF), pp.1-55.

Rigdon, E.E., 2012. Rethinking Partial Least Squares Path Modeling: In Praise of Simple Methods. Long Range Planning, 45(5-6), pp.341-358. https://doi.org/10.1016/ j.lrp.2012.09.010.

Riom, C. and Sivropoulos-Valero, A.V., 2020. COVID-19 has forced many firms to innovate, with possible lasting impacts. LSE Business Review, pp.1-7.

Riom, C. and Valero, A., 2020. The Business Response to COVID-19: the CEP-CBI survey on technology adoption. Centre for Economic Performance, London School of Economics and Political Science, pp.1-22.

Shen, H., Fu, M., Pan, H., Yu, Z. and Chen, Y., 2020. The impact of the COVID-19 pandemic on firm performance. Emerging Markets Finance and Trade, 56(10), pp.2213-2230.

Stănculescu, E., 2021. Fear of COVID-19 in Romania: Validation of the Romanian Version of the fear of COVID-19 scale using graded response model analysis. International Journal of Mental Health and Addiction, pp.1-16.

Tavares, F., Santos, E., Diogo, A. and Ratten, V., 2020. Teleworking in Portuguese communities during the COVID-19 pandemic. Journal of Enterprising Communities: People and Places in the Global Economy, pp.1-16. doi: 10.1108/JEC-06-2020-0113.

$\mathrm{Wu}$, L., Hitt, L. and Lou, B., 2020. Data analytics, innovation, and firm productivity. Management Science, 66(5), pp.2017-2039.

Zeng, D., Chen, H., Lusch, R. and Li, S., 2010. Social Media Analytics and Intelligence. IEEE Intelligent Systems, 25(6), pp.13-16. doi:10.1109/MIS.2010.151. 